\title{
Analysis on the Reform of Foreign Accounting Based on Rain Classroom
}

\author{
Bei Li
}

Shandong Women's University, Ji'nan, Shandong, China

\begin{abstract}
With the wide application of "Internet +" in the field of education, the intelligent teaching platforms such as "Rain Classroom" are gradually integrated into the classroom teaching, which can solve the deficiencies of the traditional teaching mode to a certain extent and improve the teaching effect. This paper under the background of "Internet + education", the analysis of "foreign accounting" curriculum in the traditional teaching, learning, assessment problems, and according to the existing problems, based on the "rain classroom" of "foreign accounting" curriculum mixed teaching reform, in order to stimulate students' interest in learning, make students to be more involved in the classroom, and then promote the improvement of teaching quality.
\end{abstract}

Keywords: Rain classroom, Foreign-related accounting, Teaching reform.

\section{Introduction}

To comprehensively promote the reform of higher education, the Ministry of Education of Higher Education in $2019,2020,2021$ work points of information technology and promote the depth of curriculum reform, establish "Internet + teaching", "intelligent + teaching" new form, improve teaching efficiency, accelerate the development of education information with high quality. Internet information technology is widely used in the field of education. The mixed teaching mode of intelligent teaching platform integrated into curriculum teaching, online and offline combination, and pre-class integration has become the hot direction for the innovation and development of education informatization.

\section{Rain Classroom and Mixed Teaching}

\subsection{Rain Classroom}

"Rain Classroom" was developed online by Tsinghua University United School in 2006. It combines mobile WeChat and computer courseware. It is a tool to assist teaching to provide teachers with data collection and analysis services for teaching, making the teaching process more convenient and intelligent, and has been widely used since its launch. At present, the use of smart phones for college students occupies a lot of spare time. More than $90 \%$ of the mobile phones have installed WeChat. The emergence of "rain classroom" connects mobile phones with classroom teaching and become a tool for auxiliary teaching. Its built-in functions are popular with teachers and learning, such as learning material push function, which facilitates students 'preview and review, automatic correction function of classroom practice and homework system, saves teachers' review time, data collection and analysis function, and facilitates teachers' assessment and evaluation of students. Students like its random roll call, bullet screen, voting and other functions very much. Students' enthusiasm for learning improves, and they consciously participate in the classroom.

\subsection{Mixed Teaching}

With the gradual application of information technology in the field of education, online learning has become a more common learning method outside the traditional learning methods, so mixed teaching, which first appeared in China in 2004. Professor He Kekang is the first scholar in China. He believes that mixed teaching is produced by the rise of mixed learning methods, which has the advantages of both network and traditional teaching. The teaching concept is dominated by teachers, students as the main body, namely, inspire students and control the whole teaching process; students play subjectivity in the learning process, improve enthusiasm and stimulate creativity. Mixed teaching extended the time of teaching and learning, broaden the space, give play to the advantages of online and offline mixed teaching, actively carry out the pre-class, classroom and class "online + offline" mixed teaching practice, advocate using a variety of teaching resources, technology and methods in the teaching process, is a kind of traditional teaching and network teaching advantages, emphasize the "dominant + main body" teaching mode.

\section{Problems Existing in the Traditional Teaching Process of the Foreign Affairs Accounting Course}

\subsection{Overview of the Course of Foreign Accounting}

With the continuous enhancement of China's comprehensive national strength and the deepening of opening up to the outside world, China is unprecedented closer to the center of the world stage. There are more and more foreign business such as foreign trade, foreign capital utilization and foreign operation, and the demand for professional and high-quality foreign accounting talents is increasing. Foreign accounting is a branch of accounting, accounting, auditing, financial management professional course, the course not only has the characteristics of traditional accounting, but also has its own unique, such as accounting exchange gains and losses, calculate export tax rebates, foreign currency translation, through foreign accounting course, can make students master the foreign accounting of the basic theory and methods, engaged in foreign accounting should have basic knowledge, work skills and professional quality, lay the foundation for to foreign accounting jobs after graduation, to a certain extent alleviate the shortage of foreign accounting talents in China. 


\subsection{Problems Existing in the Traditional Teaching Process of the Foreign Accounting Course}

3.2.1 Teaching: the teaching form is single, the teaching content is much and boring, and the students' learning enthusiasm is not high

In the teaching form, Restricted by the course characteristics and class hour requirements, Traditional classroom teaching mainly depends on teachers' teaching, Sometimes the "rain classroom" teaching platform is occasionally used, But only with one or two of the simple features, The teaching form is single, There is less interaction between teachers and students in class, The atmosphere is more dull, Unable to stimulate the students' enthusiasm for learning; Teaching content, The course is rich in theoretical content, It mainly lectures on the accounting treatment of foreign exchange business, import and export business, export tax rebate and other specific businesses, Students are more boring to learn, Students' subjective initiative is insufficient, Teachers should teach knowledge uniformly, Students have different knowledge acceptance abilities, The teacher's teaching progress can not take into account the situation of each student.

3.2.2 Learning: the lack of effective supervision of students' pre-class preview, classroom performance and homework supervision

Before class, the teachers are unable to substantially check the preview tasks assigned to students, and some students are lazy and lucky, thus affecting the effect of independent preview, the students' class performance, such as class questions, the homework exercises are generally required to complete after class, the problems can not be solved immediately, and the teachers cannot supervise the completion of the homework in real time.

3.2.3 Assessment: usually the proportion of results is small, the process of assessment is insufficient

"Foreign accounting" course comprehensive composition is: usually $(30 \%)+$ final results $(70 \%)$, which usually small proportion, and usually mainly attendance, homework (theory homework and training homework) assessment, can not process comprehensive evaluation of each student, the final exam proportion will lead to students before the surprise review (or for some students), rote knowledge to cope with the final exam, so for the exam can not play the original meaning of the assessment.

\section{Construction and Implementation of the Foreign Accounting Course Teaching Mode Based on "Rain Classroom"}

\subsection{Mode Construction}

The mixed teaching of the "Foreign Accounting" course based on the "rain classroom" is dominated by teachers, The student-oriented model, Teachers install a web version of "Rain Classroom" on their computer, Use the mobile phone WeChat to scan the code to enter, With the help of the "rain classroom" teaching platform, Teachers have added "Foreign
Accounting" courses and classes to the web version of the "Rain Classroom", Let the students scan the code and enter their class, According to the teaching objectives, Before the class, The teacher uploaded the prepared courseware and other preview materials to the "rain classroom", And send announcements, teaching tasks, Students should conduct pre-class preview according to the tasks; classroom, Teachers will review, teach new courses, and solve the difficulties in students' preview, Through the built-in bullet screen, voting and random roll call of "Rain Classroom", activate the classroom atmosphere and increase the interaction between teachers and students, and conduct random questions or in-court testing, Summary and consolidation; After the class, to give an assignment, And push the expansion of resources. At the end of the semester, the course assessment of the combination of process evaluation and final examination evaluation, using the "rain classroom" teachers provide detailed teaching data, to comprehensively evaluate the learning process, according to the evaluation and investigation and analysis results, adjust and improve the teaching process.

\subsection{Implementation and Application}

4.2.1 Teaching: The concept of "Internet + education" is integrated into the classroom teaching, changes the teaching mode, and integrates the teaching content

In terms of teaching methods, according to the experience of online teaching during the epidemic period, the Internet is effectively used to apply the "rain classroom" intelligent classroom teaching platform to the classroom teaching practice of Foreign Accounting. Before class, the teacher will upload the prepared teaching resources to the "rain classroom", the students receive the preview, and the students will determine the feedback of the students into the classroom, the teacher can check the students 'attendance, use barrage, classroom testing and voting, the classroom online interaction, the teacher can check the classroom participation, the teacher will post homework and students' learning resources through the "rain classroom". In terms of teaching content, teachers determine the focus of the lecture according to the feedback of students' preview before the "rain class", reduce the simple class hours that students think have understood the content, and increase the proportion of practical training class hours. In addition to the textbook content and PPT, it also includes various media resources pushed by teachers to students through mobile devices.

4.2.2 Learning: "Rain classroom" runs through before class, classroom, under class, and implements effective supervision of students' learning situation

Before class, teachers can monitor the preview progress of students at any time, remind them and answer students' comments; in the class, check the status of the class and check the class test, the teacher can check the completion and scores. Learn the overall learning situation of students through the data recorded by teachers in "Rain Classroom", including pre-class preview, classroom performance, homework completion degree and scores, etc.

4.2.3 Assessment: The evaluation mode combining online 
platform and offline classroom and diversified process evaluation with final examination evaluation

For the teaching evaluation of foreign-related accounting courses, the online feedback data of the "Rain Classroom" platform and the offline evaluation of teachers and students are used to comprehensively test whether the students have reached the teaching objectives of the "Foreign-related Accounting" course. The process evaluation of foreign accounting courses and the final examination evaluation each account for $50 \%$ of the total scores. Among them, the process evaluation items and composition are the attendance situation $(5 \%)$, classroom performance (10\%), homework (20\%), and the completion of practical training projects (15\%). The process evaluation of each student is realized by using the embedded data analysis function of platforms such as "Rain Classroom". According to the assessment, evaluation, investigation and analysis results, the teaching process is adjusted and improved.

\section{Conclusion}

Through the practice of teaching reform and investigation and analysis, shows that based on the "rain classroom" "foreign accounting" curriculum mixed teaching reform is effective, to a certain extent stimulated the students 'learning enthusiasm, actively participate in the classroom, the lesson preview gradually became a habit, cultivate the students active learning, the ability to analyze and solve problems, students' foreign accounting course comprehensive performance compared with the traditional class. The mixed teaching reform of the Foreign Accounting course based on the "Rain Classroom" teaching platform can solve the problems existing in the current classroom teaching of the Foreign Accounting course, and change the classroom teaching mode with students 'learning as the main body and teachers' teaching as the leading role. It serves for the improvement of classroom teaching effect, and also provides help for the training of foreign-related accounting professional and technical talents.

\section{Acknowledgement}

This paper is supported by the project: Shandong Women's university 2020 Teaching Reform Research Project-based on the "rain classroom" of the "Foreign accounting" course mixed teaching mode reform research stage research results.

\section{References}

[1] Li Yiping. Research on the mixed teaching model of intermediate financial accounting under the background of "Internet +" $[\mathrm{J}]$. China Township Enterprise Accounting, 2019, (10): 288-289.

[2] Fu Ling. Application of the mixed teaching model based on "Rain Classroom" in "Accounting English" teaching[J]. Journal of Ningbo Engineering, 2020, 32(1): 112-116.

[3] Wan Fei, Liu Nana. The exploration and application of the "Rain Classroom + Tencent Classroom" hybrid teaching model in the practical English classroom[J]. Campus English, 2020(24): 2.
[4] Zhao Xuerong, Ding Shi, Wang Jianping, et al. Process assessment of medical immunology based on rain classroom quantification[J]. Theoretical Research and Practice of Innovation and Entrepreneurship, 2021, (1): 37-39. 